\title{
Duas vezes Baudrillard: da guerra à guerra, ou o lugar do ausente André Quciroz ${ }^{*}$
}

\section{RESUMO}

No presente artigo, procuramos discutir a noção de contra-acontecimento utilizada por Jean Baudrillard ao avaliar a Guerra do Golfo, a de 1991 e a de 2003, assim como ao caráter virtual dos acontecimentos meteóricos promovidos no espaço de nossa sociedade informacional - e isto como tática de dissuasão de toda e qualquer forma de alteridade inscrita no presente.

\section{ABSTRACT}

In this article, we discuss the notion of counterevent used by Jean Baudrillard, in his evaluations of the Gulf Wars of 1991 and 2003, to refer to the virtual character of the meteoric events occurring in the sphere or our information society, seen as dissuasive tactics directed to any kind of alterity inscribed in the present.

\footnotetext{
* Professor do Programa de Mestrado em Comunicação, Imagem e Informaçāo da UFF. Doutor em Psicologia Clínica pela PUC/SP. Autor de A Morte Falada (1998), Foucault - o paradoxo das passagens (1999), Tela Atravessada - ensaios sobre cinema e filosofia (2001) e de O Presente, o intolerável - Foucault e a história do presente (2003).
} 
Poderíamos começar o texto tomando como suporte o lugar de uma insistência, o Iraque, ou a guerra que lá se credita. Lugar e fato. Espaço do acontecido, ou antes, da recorrência de uma narrativa que para lá arremessa as peças de seu fabulário de controle. Lugar e invento - menos lugar, e mais o seu fabrico na montagem do discurso. O Iraque, e já dele, um outro - como cartografia das guerras, as duas. Entre os dois acontecimentos editados, algo mais do que a dezena de anos - 1991 e 2003. O Iraque como lugar-alvo, sua personagem na trama, antes mesmo do que uma sua disponibilidade como cenário: as cidades tomadas de poeira de uma história milenar - $\mathrm{e}$ isto bem distinto de nós (o outro daquele distante; nós, este que narramos, o que é dizer, nos termos de Nietzsche, este que cunhamos valores; aquele, o que se perde na sombra impenetrável, ponto cego de nossa visada), ou da nossa fatia histórica: seu recorte, o dentro positivante de seu saber, ou de sua ordre $d u$ discours. E então, este outro lugar de que também poderíamos começar o ensejo analítico, este nós, os recentes, este que envergamos o rótulo do novo - o descoberto de ainda, o inventado no ontem do mundo. Maravilhoso mundo novo, a América recente e quase mítica, espaço de deslocamento de povos inteiros na construção de suas alteridades desterradas - horizonte de fuga, ou de translado: italianos, espanhóis, portugueses, eslavos, polacos, e até mesmo árabes, turcos, libaneses, os antigos, ou gastos, ou irredutiveis outros na fronteira da exclusão (e a Europa como limite, a curva radical do mapa; Le Pen como subtexto) - o outro do nós, aqui e já dentro, no umbigo

128 do tempo. Nós, os modernos. Fragmentados seria o caso? Um tanto isto na angulatura que se nos dá a ver na escritura crítica de Jean Baudrillard. Fragmentado, então, como a dissolução saturada de qualquer valor rumo ao seu estágio de grau zero - o invalor, ou a indiferença como o pathos ocidental deste fin-de-siècle, e já mesmo como paradigma frágil do milênio que se inaugura. ${ }^{\prime} \mathrm{Ou}$, por outra via, como um outro este fragmentado; sua movença desterritorializada como condição/humus, como solo de imanência para uma literatura de intensidades inauditas. Eé já Deleuze a nos falar de forma afirmativa da literatura anglo-americana, a escritura do nós: “(ela) apresenta continuamente rupturas, personagens que criam sua linha de fuga, que criam por linha de fuga. Thomas Hardy, Melville, Stevenson, Virginia Woolf, Thomas Wolfe, Lawrence, Fitzgerald, Miller, Kéruac. Tudo neles é partida, devir, passagem, salto, demônio, relação com o de fora. Eles criam uma nova Terra" (1977, pp.49-50). Duas leituras distintas desta fragmentação que experimentamos, a de Baudrillard e a de Deleuze. No cerne do olhar, o nós de que tratamos, de passagem, como fragmentado. Aquele, o seu Outro irredutível, o pleno de arcaísmos, a traçar o mapa de uma conduta que nos escapa de todo. Lugar do sacrifício, do desacelerado, da sacralidade engolfante desde a qual, e na qual, tudo parece comum. Lá fora, nas fronteiras do outro, os bárbaros - os outros do outro de nós. Ou o Mal. E então, desta 
vez e ângulo, o Ocidente, nós, como o Mal. Esta insígnia móvel a deslizar de um lado a outro, o Mal. Aqui e agora, nós. Já e tão logo, eles. O Mal, este distintivo fluido, escoado, volátil. Aqui, a América e sua tecnologia de aceleração. E sua voracidade de consumo. E sua máquina de guerra demoniaca. Lá mesmo, neste Iraque das guerras, personagem de assalto e/ou pilhagem, é do excesso de história a matéria da qual se padece - excesso como mistura e esgarçamento. Não o excesso como o antiquíssimo dos registros, mas como a lateralidade vazada pelas interferências. O Oriente Médio, esta zona tórrida de infiltrações. Israel - pólo avançado do Capital transnacional. O Iraque, logo ali - sua miséria de devastação, seu poderio bélico de fazer rir, sua história como derrame, e infiltração. Ou o que é dizer: a história como inclusão nos programas desta América - Saddam, e também, a Al Qaeda, como receptáculos de verba e armamentos norte-americanos. A despeito de tudo, uma (nossa) deriva é já o que voltamos a indicar: nem o nós, nem o eles, lugares em vertigem, lugares sem lugar, tão logo re-focados os intérpretes e os avalistas, e de tal forma isto, que pouco ou nada nos restaria do suporte que sugeríamos à visada ensaística, mas qual o suporte, o do acontecimento (a pergunta que insiste é pelo lugar) - ou aquilo que servisse de solo para o depósito do fato. Este a mais, ou aquém, com relação à narrativa que dele se apodera ao the conferir sentido, ao aprisioná-lo numa imagem de pensamento, ao congestioná-lo numa raison d'être. Mas qual o lugar que restasse na resistência recuada em face de qualquer escrutínio, de qualquer discursividade? Ou seria abusiva, e sem terra, a pergunta pelo lugar em resto, em sobra, em recuo - lugar do acontecimento, lugar em reserva; o campo de imanência no qual narrativas e práticas não fossem mais do que fatias do real, efeitos de superficie, contingências forçosas em um campo pontual e estratégico de forças e de agenciamentos políticos, conexões de possiveis em atualização, mas que não esgotassem do presente aquilo que lhe cabe, desde o recuo de que falamos, ou seja, uma outra via e cenário, diagramação vária, a criação de novos possiveis, o acontecer de outros acontecimentos para lá do sufocamento, e do intolerável do qual responde nossa presença atual - uma invenção do futuro?

Ainda assim: poderíamos insistir em avaliar a este lugar-personagem, o quase-cenário de duas guerras - o Iraque no entre dois pólos de conduta Ainda ontem, a zona de ingresso num Irã pós-1979 - o Ocidente chegando pelas beiras, e brechas, fazendo pelo Iraque a sua cerzidura - fronteira móvel, pista de pouso, campi avançado. Nos chassis dos tanques militares, a patente, a inscrição de proveniência - digital suja e deflagrada. Ou menos ainda, e de forma mais cínica, o Iraque como espaço de circulação des-ideologizado do capital bélico americano - suas fronteiras como passarelas, seu solo como superficie de desfile, seus soldados como top models na condução perfeita 
do arsenal da "alta-costura" militar. Espelho equívoco do outro e de si, este Iraque, na mostração de uma razão publicitária - e todos os signos inscritos na pele em ex-posição. Como também o fora o Chile de Pinochet para o ideário neoliberal - cobaia, vitrina, ensaio. ${ }^{2} \mathrm{E}$ agora, este agora de década $\mathrm{e}$ dois anos, o Iraque como o Outro, personagem diferido, heterônimo radical, tão agora, e desde sempre. O paradoxo encenado para além da evidência mediática. E doutro modo, aqui, evidência toda ela publicitária - sob o fogo fátuo do bombardeio massivo de imagens e de discursos. Qual seja? O Iraque como o paroxismo a que se pode chegar na condição de alteridade: o Outro como contra, risco, perigo, ou o que é dizer, como aquilo que se deve eliminar sob o pretexto da prevenção. Lugar-depositário do Mal. Este encarno, o do $\mathrm{Mal}$, como lugar em depósito. E eis o reverso da visão, o Iraque, o Mal, e leiase no equívoco já impresso em distinção e disritmia, o Iraque/Islã (mesmo que ele se dê, este juntado de partes distintas, em defasagem e desmarcamento; Iraque/Islã: esta fusão de conveniência, este fabulário sem terra, este fundamentalismo de inacontecença - na hora avançada do enredo), o Iraque como o Mal desde a América em sua dramaturgia pós-moderna (sob a letra precisa de Bush), desde o fragmentado assolado em sua indiferença, ou o jogo/jorro do múltiplo (indivíduos/consumidores e capitais volatilizados) para o qual toda e qualquer verticalidade díspar de transcendência possa sugerir o incômodo radical. O incômodo terrorista. O Iraque como o Mal. ${ }^{3}$

Poderíamos nos situar no cenário insistido: este Iraque em pontilhados. E mesmo Saddam seria um personagem travestido com double face, ou o ator ilusionista, travesti de um e de outro - a escoar sem peias no vértice que lhe convenha à hora. No entanto, qual seria já o lugar de mira do cálculo obstinado da argumentação? Este lugar (i)móvel, o substrato precário, sedimentado apenas o suficiente que comporte a referência daquilo mesmo que se diz? - a questão recorrente. $O$ discurso, a rede de fundamentação lógica, alguma geopolítica razoável? - efeitos de superfície. Qual seria este lugar de um lugar que resistisse ao trato das horas e ao deslocamento dos intérpretes - se mesmo a história de milênio num Iraque antiquíssimo poderia se fazer subsumida na variança das cores em profusão, num de-situar de posição $\mathrm{e}$ de argumentos, no virtual sem espaço da política contemporânea?! Falar do Iraque seria insistir num lugar de alvo, e este parece ser menos do que o Iraque, ou menos do que seu povo, ou Saddam e seus comparsas. Sempre menos - esta graduação em que se faria valer ação e discurso. Como num trompe l'oeil. ${ }^{4}$ Já e já, outro. Miragem, simulacro, esquecimento. Já e já, um outro. Cenário e cena num embaralhar de peças no caleidoscópio. O Iraque e não, o Iraque. Saddam e não, Saddam. O armamento químico/biológico e não, o armamento químico/biológico. $O$ fomento estatal do terrorismo e não, o fomento estatal do terrorismo. ${ }^{5}$ Sempre menos, e já quase um outro o que se 
daria do quadro em defasagem - O Iraque e quem sabe, a Coréia do Norte, o Irã, ou o Afeganistão de ainda há pouco e de outra vez, ou Cuba como fabulação rediviva nos processos contra a ditadura democrática dos direitos do homem, ou contra o que for... e isto sob a suspeita antecipada desde sempre ${ }^{6}$ Como um a priori com relação às provas, aos oficios, às comissões, $e$ às inspetorias. O mecanismo das provas sendo desarticulado, do inicio ao fim, no quando da condenação espetacularizada. Como se o tribunal de sentença prescindisse das peças judiciárias e o veredicto estivesse sempre lá, em recuo em face da história, em precedência com relação aos acontecidos, em resguardo virtual da intoxicação possível dos fatos. Paroxismo da condição do olhar que historiografa: se trataria agora não de deixar baixar a poeira dos fatos como cláusula de isenção possível, ou de neutralidade, ou de não distorção (míope) na impressão do texto. Agora, um outro: não deixar que a história no que ela reserva de rasto, de resíduo, de contenda possa sujar as lentes do avalista/especulador que circula num nível de desterritorialização tamanha que qualquer mapa possa vir a constranger. A sentença se dando a despeito dos fatos. Ou mais, na indiferença com relação a eles. Ou mais, na antecipação inadvertida dos mesmos. Como numa gestão do futuro, numa intoxicação contumaz dos possiveis. Na recorrência de um presente sem fim, ubiquo. Este mesmo, o intolerável.

E aqui já começamos a nos desfocar do objeto a que não nos propomos avaliar neste ensaio - qual seja, a guerra, as duas, ou o Iraque como alvo insistente. $\mathrm{E}$ mais, começamos a vislumbrar o que queremos por trás do embaçado do campo de visão. Ou seja, situarmo-nos às bordas dos textos, trespassando-os por vezes, ou arriscando uma deriva, outra, com relação a eles - mas quais, os textos? Os dois textos de Baudrillard: A guerra do Golfo não terá lugar (1991) e A máscara da guerra (2003) - escritos na esteira dos conflitos, e um tanto na descrença deles, no anúncio de uma desfaçatez: aquilo que eles sugeriam acerca de si, o seu acontecimento radical. Bem menos do que isto, a guerra. As duas. Esta última, que assistimos, seria mesmo, segundo Baudrillard, uma forma de contra-acontecimento. Algo que se dá na intenção de conjurá-lo, dizemos, ao acontecimento - e Jean Baudrillard pontua este que não se quer ver, este que se quer apagar: o 11 de setembro. Apagamento condenado em sua pretensão e eficácia, uma vez que ele visa, obstinado, à retroação do fato, como se fora a memória do acontecido não mais do que pergaminhos encharcados aos quais ao se lhes enxugar, se aniquilaria por completo todo o traçado. Mas como este efeito/antidoto no depois da hora em que o acontecimento, radical em sua incerteza afirmada, na ruptura de qualquer sentido que o contenha em sua descontinuidade, já se imiscuiu ao mundo? O 11 de setembro no alargado de sua duração - o desabamento das torres gêmeas como ato simbólico maior, como performance 
par excellence do Capital. Baudrillard afirma que o acontecimento é aquilo que promove uma cisão em sua acontecença ao desmarcar-se dos campos de referência - todo e qualquer. E daí, a sua incontestável radicalidade. ${ }^{7}$ A impossibilidade de sua escrita, a do acontecer do acontecimento, num sistema generalizado de troca.

Em um artigo para o jornal francês Le Monde, Baudrillard nos indica um equivoco de interpretação na leitura do ato de terrorismo do 11 de setembro - minimizá-lo com vistas ao que ele pode. Como se se tratasse de um golpe certeiro no seio da nova ordem mundial e então, no revés do ato, a recrudescência da máquina de guerra imperial a se voltar contra o invasor. Imprecisão de leitura, ou tentativa escamoteada de condenação da cena 11 de setembro... dizer da ira do Império a equivalência da agressão do invasor. Qual, e como, e quem? Este rosto impreciso, o do invasor, traços numa errância de movimento, o invasor, este rosto disforme como os de Francis Bacon - o pintor, arranjo sem terra ou idéia; o ato ou o invasor - a quem se destinaria a ira do Império senão ao primeiro, e então, de forma irrevogável, conjurá-lo, apagá-lo, como no duelo imponderável de Dom Quixote com os fantasmas, as incongruências. Baionetas contra moinhos de vento, ou melhor, mísseis Cruise, drones teleguiados, F-117 unidos contra o ato do 11 de setembro. Mas qual? E como? E para quê? O delírio em revanche do Império não esgota o que pode $o$ ato, tampouco $o$ condena em sua obstinada fatalidade - inscrever-se inelutavelmente como ruina simbólica ao poder desmesurado da América. ${ }^{8} \mathrm{O}$ delírio fascista de Bush, e seu intento em ser polícia do mundo, diz antes respeito à condenação mesma de sua utopia de ubiqüidade securitária: prevenção, dissuasão, controle total. Internamente, a tolerância zero do Estado-penal pós-Welfare e a criminalização da miséria, e da alteridade. Toda e qualquer, ou a que couber na alcunha da periculosidade - traços de conduta, diagramas de caráter, filamentos do código genético. Externamente, a exportação de uma guerra sem fim, e a inevitável demonização do outro, o arcaico, o desumano, o bárbaro. Todo e qualquer, ou o que couber na alcunha do terrorismo - o armamento químico/biológico, o fanatismo religioso, a ditadura anti-mercado livre. Nas palavras de Baudrillard: “... trata-se de supor que toda violência adversa é finalmente cúmplice da ordem existente, o que desqualifica as intenções dos atores e a própria razão da ação. Vincula-se a ação às suas conseqüências 'objetivas' (as consequêencias geopolíticas do 11 de setembro) e nunca à sua potência própria" $(2003$, p.27). Outra vez, dizer do acontecimento o que lhe cabe: o desmarcamento do sistema de troca. Logo, o terrorismo imperial a se voltar contra o Afeganistão (ou menos do que isto, contra a Al Qaeda e Bin Laden, ou menos do que isto... e o menos é sempre), ou contra o Iraque (ou menos do que isto, contra Saddam, ou menos, e é sempre menos) não seria esta oferenda em recurso, esta troca em 
equivalência, pelo contrário, seria apenas o reforço da perda irreparável, o seu espraiar em ressonância a acentuar ainda mais o nonsense a que se remete a nova ordem, ou seja, a especulação desenfreada do Capital - ele próprio desterritorializado e desterritorializante. ${ }^{9}$ Numa das partes, este desenfrear equívoco, a pulverização do inimigo (este que se inventa, a rostidade que se faz decalcar sobre a incongruência) ao ponto de seu desaparecimento total, e como é menos o de que se trata sempre em escala de ação e discurso, esta pulverização e este desaparecer é antes no nível mesmo da tela do que de sua inscrição no real histórico - Bin Laden e Saddam Hussein a vagar, virtualizados em fitas, em entrevistas e falas sem data, sem local, desterritorializados também eles, e por isto, fantasmáticos, leia-se: simbólicos e inencontráveis. Noutra parte, aqui e neste instante da globalização, o que se universaliza é a guerra preventiva e perpétua, ou a sua função contraceptiva, a guerra de prevenção em que a segurança como razão maior dos Estados na sua função de gestão interna do medo e da incerteza, se volta para fora, em direção ao mundo inteiro, contra o Outro (todo e qualquer, virtual ou real, a quem se teme, e se odeia), contra o futuro como parturiente de possíveis. ${ }^{10}$ Outra vez, a expressão que cabe à hora, o invaginar destes possiveis na tática fascista e paranóica do Império. Eis o que Jean Baudrillard localiza como sendo a estratégia final, ou o móbile do conflito para além do que se enunciara sob o pretexto do combate ao crime, ao Mal, ao terrorismo: “... instaurar uma ordem securitária, uma neutralização geral das populações com base na afirmação de um não-acontecimento definitivo" (2003, p.71). Não apenas a retroação, o 11 de setembro mergulhado no luto que não se ultrapassa, mas todo e qualquer acontecimento engolfado desde antes, desde logo e sempre, na sua virtualidade. Como que para abortá-lo in vitro, ou para encerrá-lo em um controle abusivo de assepsia. Isto pode, isto não pode: $O$ Iraque não pode, Cuba não pode, a negativa do conselho de segurança da ONU não pode; a experimentação desumana nos cárceres de Guantánamo, o multiplicar dos saques de um povo entregue às ruínas e o controle dos poços petrolíferos pelo governo do Império - um seu destacamento de homens e base, isto pode. Ou ainda mais, na filtragem do que não pode, a extensão de um presente perpétuo de condenação - isto jamais poderá, ou então, isto jamais será perdoado (leia-se: esquecido, tragado, digerido). E na sua radicalidade máxima de expropriação: jamais poderá, jamais caberá os istos que agora faltam (matéria de invenção, ou fabulação, os possíveis em desmontagem do intolerável - linhas de fuga deleuziana). O 11 de setembro parece reforçar ao extremo este tempo de encenação repetida, e repetida, e repetida. De forma compulsiva, a repetição das imagens das torres gêmeas implodindo. Uma de cada vez. Uma depois da outra. E outra vez, e novamente - quem sabe se na busca do ângulo perfeito (espécie de retoque no acontecido), ou no trabalho de anamnese sobre um algo que possa estar 
perdido à imagem, mas qual este algo, ou este dentro, ou este fundo, se a imagem prima por sua anorexia?! E se ela, a imagem, apenas remete à outra, e outra, numa cadeia de remissão ao infinito - estando ela conformada à condição zero de espessura ?! Eterno retorno da imagem em rede como que num esticar ao limite o presente. Espécie de campanha publicitária mórbida na qual e pela qual se firma o pacto simbólico entre os reféns - todos nós. Eis o painel/retrato, ou o tabuleiro de peças - o diagrama das forças em sua configuração atual: estarmos sob o alvo da tela total - lugar de despressurização do acontecimento. Sob o alvo dos enunciados e do mundo que se descortina desde as ilhas de edição, e desde os textos colados às imagens editadas." "Bombeiros missionários, chefes de família inocentes, gente como nós, e aqueles outros, terríveis e detestáveis, irredutíveis outros do centro fechado de seus véus, costumes e arcaísmos, os enviados do Mal, os agressores. Nós, a vítima inconteste. Mas do quê? Do fato, ou desta leitura/ remake superposta em apagamento do que possa haver de efeito de real? ${ }^{12}$ Vítimas, ou reféns - nós, eles, todos? Baudrillard não hesitou em sugerir a segunda hipótese. No texto de 1991, sobre a primeira fatia de uma guerra de inacontecença, Baudrillard nos situará aí neste espaço de pura inatividade. $\mathrm{Na}$ "guerra-morta", o refém parece tomar o lugar do guerreiro, ele é "o atorfantasma, o figurante que ocupa o espaço impotente da guerra" (1991, p.107). Assim como mais tarde falará da prevalência do virtual sobre o real (este, como efeito) no cenário de 2003, também aqui, no texto de 1991, será este o 134 lugar sem lugar de nosso exílio, "a informação, ela própria, o terreno", areia movediça em que depositados os pés se nos vemos paralisados, e em (seu) consumo, reféns estratégicos da profilaxia operacionalizada pela górgona mediática.

Uma vez mais, o paroxismo de nossa condição é o que atesta o olhar arguto de Jean Baudrillard: reféns da câmara de despressurização do acontecimento - os media e seu espaço virtualizado, e a um só tempo, nela buscando o nosso exílio, ou algum solo, quando é justo de seu desaparecimento que agonizamos, e ainda, que sufocamos - na medida em que o presente perpétuo engendrado revoga todo e qualquer possível, o que apontamos ser a gestão do futuro: este seqüestro não mais dos corpos pelas práticas institucionais tal como nas sociedades disciplinares a que se referia Michel Foucault, seus dentros totais e de máxima saturação, os das instituições como a caserna, o asilo, a fábrica, a prisão; claustros de ingresso, o seqüestro à época. Aqui e agora, não mais esta formatação. Espaços abertos, clausura desfeita, e livre circulação - das gentes, do capital, da comunicação. E ainda assim, seqüestro e reféns. Não mais em reclusão no governo do tempo das horas, e da medida distributiva no mapeado do espaço. Aqui e agora, um outro. Seqüestro do acontecimento - liberação da via pública, da pólis deixada 
à solta, mas desfeita do que ela pode no conluio das gentes em governo de si. Resguardo do acontecimento na sua antecipaçào obsessiva no tempo sem tempo da informação desterritorializada (em tempo real? - este paradoxo, esta aberração!), e repetida, e repetida, no engolfamento de qualquer acaso. E é Baudrillard a dizer da guerra, este contra-acontecimento, de sua programação, de sua antecipação a tal ponto que sequer poderíamos esperar do acontecimento um seu efetuar para além, ou para aquém, de sua prévia, em maquete móvel, em 3D, de estúdio - demiurgia contemporânea no fabrico do real, ou na injunção enunciada de imprimatur ao acontecer do acontecimento: faça-se imprimir! Ao acontecimento resta acontecer, ou menos do que isto, confirma-se e conforma-se em acontecer. Nos termos de Baudrillard, acontecimentos clones (2003, p.70). Noutro texto, eis uma passagem esclarecedora: "Todos os media vivem da presunção da catástrofe, da iminência suculenta da morte. Assim, uma fotografia do Libération mostranos uma coluna de refugiados 'que algum tempo depois será atacada pelo exército iraquiano' (...) Antes dizia-se, para desmascarar o artificio: é cinema! É teatro! É literatura! Desta vez foi possivel dizer, perante a Romênia e a guerra do Golfo: é televisão!" (1992, p.85 - grifo do autor). Na outra ponta do novelo, nós, eles, todos, os reféns. Deixados à solta no espaço da pólis - em errância, prisioneiros da passagem, menos circunspectos que indiferentes, passivos muito mais do que passionais, inertes mas em regozijo desta condição, a de consumidores simbólicos, ou mais, a de consumidores reais de acontecimentos meteóricos - a guerra/game, o episódio da novela, o texto sem textura dos realities shows, a farra eletrônica dos votos nas cenas eleitorais, ou o que for... $\mathrm{Na}$ expressão de Virilio, este o tempo de homens superexcitados em lugar do inatual do além-do-homem de Nietzsche - não a transvaloração de todos os valores no fazimento de um porvir não intolerável, mas a invaloração/involução de qualquer valor, e de forma tal, que todo paradigma ético/estético na construção de novas subjetividades estivesse logo fadado à condição de incongruência. ${ }^{13}$ Nas palavras de Baudrillard, "gente enervada, isto é, simultaneamente superexcitada e indiferente, tetânica e apática" (ibid, pp.30-31). Reféns, todos, e em asilo na vacância generalizada de uma condição aterradora, a da ausência de lugar do acontecimento tornado obsceno, aquilo a que se deve extirpar desde sempre - este o quadro.

Talvez seja o caso dizer que não é mais da guerra que se trata se se pensar numa política de dissuasão sobreinvestida no agora - o que sugerirá Baudrillard. Se fosse da guerra, ou do desequilíbrio entre os Estados no plano das forças e do trato militar, seria indiscutível esta virada de mesa no corpo do presente, qual seja: ainda ontem, a guerra fria trazia consigo o acontecimento da guerra congelado pelos riscos que um seu espocar poderia deflagrar, e eis que o clássico argumento do equilíbrio das partes vingava na manutenção do 
paradoxo-quanto mais, menos. O mais do armamento, e de seu poderio, e do investimento massivo na tecnologia bélica. $O$ menos da guerra em execuçãoo para além dos testes, e da mostração do que se pode atingir. De um lado, a América. Do outro, seu contraponto soviético. E nesta soma de partes, a homeostase, o zerado da ação. Hoje não mais... E então, do desequilíbrio inconteste, $\mathrm{o}$ irreversivel do acontecimento da guerra - esta, a outra, e outra mais? Guerra perpétua, ou estado de guerra sem fim?! Parece ser deste lugar de avaliação que Paul Virilio sugere com temor e assombro: "A propósito do conflito do Kosovo, e qualquer que seja o seu resultado, coloca-se, pois, a questão - ocultada desde a falsa-vitória na guerra do Golfo - de um desequilíbrio do terror em que a infinita disseminação das armas de destruição maciça não deixará lugar para a dissuasão entre Estados" (1999, p.15). Virilio vislumbra o fim de um cenário - este dos Estados no duelo de partes, e entre eles, esta trava erigida, os pés amarrados ao freio, o equilibrio dissuasório, a guerra sempre adiada para amanhã. E então, este hoje pesado em que parecemos oscilar no interior de uma vontade irrevogável de conquista e de domínio - a vontade imperial. Um novo colonialismo entre Estados? A América como capital do mundo? Menos do que isto, e já um tanto isto mesmo. Menos do que a dominação imperialista dos Estados, e mais a livre circulação no espaço volatilizado dos mercados financeiros - ingerência invisível e ubíqua. Guerra sem fim ou estado permanente de guerra - nas agências de informação internacionais, nas telas prospectivas, e vez ou outra, nos desertos, ou nos escombros das cidades?! A questão do inimigo como aquilo que se dispõe em invento continua a valer. Sob a tutela da precariedade, e da obsolescência, a tarefa de produção deste outro que se odeia a partir de agora e desde sempre. Como a da sugestão da Albânia no filme Mera Coincidência do diretor Barry Levinson (EUA/1997). ${ }^{14}$ Aqui e agora - O Iraque em seus contrastes? Como os Balcãs? Ou a Argentina em suas mazelas? Ou a África inteira? Quanto vale isto no aleatório especulativo das bolsas de valores - esta investidura de ação, a promoção da guerra, ou a sua execução, ou o manter-se por lá (lugar do conflito? - qual conflito? Qual lugar?) no agendamento político do depois? Qual a margem de oscilação a que se pode atingir em superáficit performático, espécie de capital simbólico? Baudrillard falou da Guerra do Golfo, a de 1991, como guerra morta, guerra anoréxica, acontecimento pálido - guerra que não teria lugar. Como esta de ainda há pouco. Ou como a invasão no Afeganistão. Ou Kosovo. Guerras que estarão fadadas a este contrasenso: lá mesmo se fazer, e ainda assim, estar na errância do sem lugar. Ontem e já não mais, este cenário e personagem. Hoje e ainda não, aquele. Entre o não mais e o ainda não, zona sem pontilhados, plasticidade em desmonte de rosto, o intersticio a vontade imperial, no desgoverno de si, urdindo de forma minuciosa a tecitura do intolerável. O que é dizer: presente total, quadratura única na leitura da prosa do mundo. No corpo mesmo deste presente cerzido, a dissuasão opera, 
silenciosa ou loquaz, o inacontecer da alteridade, toda e qualquer.

\section{Bibliografia}

BAUDRILLARD, J. (1990) A Transparência do mal - ensaios sobre os fenômenos extremos.Campinas: Papirus Editora, 1990.

(1991) "A guerra do Golfo não terá lugar". In: Guerra virtual, guerra real - reflexão sobre o conflito no Golfo. Lisboa: Ed. Passagens, s/d (pp.105-1/3).

Lisboa: Terramar Editora, 1992.

.(1992) A ilusão do fim ou a greve dos acontecimentos. . (1997) A Arte da desaparição. Org. Kátia Maciel. Rio de Janeiro: Editora UFRJ, 1997. (2000) Senhas. Rio de Janeiro: Difel Editora, 2001. (2002) "Hipóteses sobre o terrorismo". In: Power inferno. Porto Alegre: Editora Sulina, 2003. (2003) "A Máscara da guerra". In: Power inferno. Porto Alegre: Editora Sulina, 2003.

DELEUZE, G. (1977) "Da superioridade da literatura anglo-americana". In: Diálogos. São Paulo: Editora Escuta, 1998.

DELEUZE, G. \& GUATTARI, F. (1984) "Mai 68 n'a pas eu lieu”. In: Les Nouvelles. Paris, 3-9 de maio de 1984.

HABERMAS, J. (1990) "Podemos considerar a Guerra do Golfo como elemento catalisador de uma nova mentalidade na Alemanha". In: Passado como futuro. Rio de Janeiro: Tempo Brasileiro, 1993 (pp. 19-40).

LYOTARD, F. (1972) "Capitalismo energúmeno". In: Dispositivos pulsionales. Madrid: Editorial Fundamentos, 1981 (pp.09-50).

RANCIÈRE, J. (2003) "A lógica da amnésia". In: Folha de São Paulo, Caderno Mais! São Paulo, 25 de maio de 2003 (pp.14-15).

SONTAG S. (2003) "Uma guerra sem fim" - uma entrevista. In: $O$ Globo. Rio de Janeiro, 01 de junho de 2003 (p.43).

VIRILIO, P. (1993) Espaço Crítico. Rio de Janeiro: Editora 34, 1993. . (1993b) A Arte do motor. São Paulo: Ed. Estação Liberdade, 1996.

2000 . (1999) Estratégia da decepção. São Paulo: Ed. Estação Liberdade,

\section{Notas}

1 Cf. Baudrillard, 1990, pp. 10-12.

2 Como afirma Perry Anderson, "o Chile foi a experiência-piloto para o novo neoliberalismo dos paises avançados do Ocidente" (p.20).

3 Cf. Baudrillard, ibid, pp.89-96.

4 Vejamos este parágrafo de Baudrillard (1997): "No trompe-l'oeil não é o caso confundir-se com o real, é o caso de produzir um simulacro em plena 
consciência do jogo e do artifício - imitando a terceira dimensão, lançar a dúvida sobre a realidade dessa terceira dimensão -, imitando e ultrapassando o efeito de real, de lançar uma dúvida radical sobre o princípio de realidade" (p.18).

5 Sobre o "esquecimento" do Império, ver o ensaio de Jacques Rancière, $A$ Lógica da Amnésia (2003).

6 Também Habermas parece por em questão esta pretensão universalista da visada ocidental, vejamos este trecho de sua entrevista a Michael Haller (1990): "Será que os princípios do direito dos povos estão a tal ponto entrelaçados com os standards de uma racionalidade ocidental, de uma racionalidade que de certo modo impregna a cultura ocidental, que não podem ser tomados como base para uma avaliação imparcial de controvérsias interculturais? Será que atrás da pretensão universalista, por exemplo, que ligamos com os direitos humanos, não se esconde um instrumento especialmente sutil e falso de dominação de uma cultura sobre as outras?" (p.31 - grifo nosso). E mais adiante: "Certamente todos concordam em afirmar que a idéia de uma ordem burguesa mundial justa e pacífica não possui nenhuma base filosófico-histórica. (...) Finalmente, elas (as forças do Ocidente) teriam que superar a consciência imperialista, segundo a qual o Ocidente não pode aprender nada das outras culturas e propor-se a um entendimento simétrico entre as culturas" (pp. 33-34).

7 Aqui aproximamos esta ruptura/cisão de que fala Baudrillard acerca do acontecimento na sua abismalidade radical, ao que do acontecimento diz Deleuze/Guattari - uma abertura do possível como criação. Notemos este parágrafo de Mai 68 n'pas eu lieu (1984): "Em fenômeno histórico, como a Revolução de 1789, a Comuna, a Revolução de 1917, há sempre uma parte de acontecimento: irredutivel aos determinismos sociais, às séries causais. Os historiadores não gostam desse aspecto: eles restauram causalidades $a$ posteriori. Mas o próprio acontecimento está separado ou em ruptura com as causalidades: é uma bifurcação, um desvio em relação às leis, um estado instável que abre um novo campo de possíveis". É bem verdade que, em Deleuze/Guattari, o conceito de acontecimento diz respeito ao campo ontológico, o que parece escapar à leitura de Baudrillard.

8 Muito menos do que recrudescência, elou revanche, é o que afirma Susan Sontag acerca da invenção do terrorismo como grande outro: "Há um inimigo ainda mais vago que o comunismo. O terror pode estar em qualquer lugar. Não é sequer necessariamente associado a um país em particular. Claro que este é o tipo de retórica usada para construir uma noção de guerra sem fim. A chave para a noção de guerra contra o terrorismo é o uso da palavra guerra. (...) E, assim, Bush anuncia que a primeira vitória na guerra contra o terrorismo foi a conquista do Iraque. E isso nada tem a ver com a realidade. (...) Querem é ter quatro bases permanentes no Iraque. $\mathrm{Na}$ 
minha opinião, este foi o motivo pelo qual o Iraque foi escolhido: era o mais fraco dos países do Oriente Médio e aquele que tinha o mais odiado ditador. Tinha um exército muito fraco e não tinha armamentos. E os americanos sabiam disso. Fingiam que era uma ameaça, mas era o oposto" (p.43).

9 Este o axioma do Capital, como atesta este parágrafo de Lyotard (1972): “(...) E assim não há mais do que uma enorme desordem em que os objetos aparecem e desaparecem sem cessar, dorsos de golfinhos à superficie do mar, em que a sua objetividade cede à sua obsolescência, em que o importante tende a já não ser o objeto, concreção herdada dos códigos, mas o movimento metamórfico, a fluidez. Não o golfinho, mas o rasto que se inscreve à superficie, a marca enérgica"(p.19).

10 Nas palavras de Baudrillard (2003): "(...) todas as estratégias de segurança são apenas uma extensão do terror. Nisso consiste a real vitória do terrorismo, ter mergulhado todo o Ocidente na obsessão pela segurança. (...) a rede policial planetária equivalendo à tensão de uma guerra fria universal, de uma quarta guerra mundial inscrita nos corpos e nos costumes" (p.47).

11 Vejamos este parágrafo de Virilio (1993): “... lá onde a pólis inaugurou um teatro politico com a ágora e o fórum, hoje nada resta além de uma tela catódica onde se agitam as sombras, os espectros de uma comunidade em vias de desaparecimento, onde o cinematismo propaga a última aparência de urbanismo, a última imagem de um urbanismo sem urbanidade em que o tato e o contato cedem lugar ao impacto televisual" (p.14).

12 Eis um traço do nietzscheanismo de Baudrillard - o trabalhar no aquém da verdade, na ausência de seu esteio. Aqui, a preferência por falar de um efeito de real como de um efeito de verdade. Vejamos este trecho (2000): "Podemos, certamente, pretender que exista um efeito de real, um efeito de verdade, um efeito de objetividade, mas o real, em si, não existe" (p.41). A noção de hiperrealidade, de realidade virtual, como o que ocuparia este lugar do real (em seus efeitos, em seus valores) sendo a assunção do homogêneo, do perfeito, do controlado. Ou o que seria dizer, o pensamento único, a totalização, a realização perfeita na qual não há espaço/condição de possibilidade para sequer "um outro lugar", ou a alteridade.

13 Sobre esta condição da contemporaneidade como o tempo da superexcitação do homem em lugar da transvaloração, ver Virilio, 1993b, pp.89114. Ou ainda Virilio, neste pequeno trecho (1993): "Se é possivel falar de crise hoje em dia, esta é, antes de mais nada, a crise das referências (éticas, estéticas), a incapacidade de avaliar os acontecimentos em um meio em que as aparências estão contra nós" (p. 18).

14 No filme de Barry Levinson se trata de produzir em estúdio uma guerra contra a Albânia ("Alguém já viu algum albanês andando na rua?" - pergunta o produtor/personagem) para alavancar a campanha de reeleição presidencial depois que um escândalo (remissão ao caso de Monica Lewinski) abalou a 
candidatura do titular da Casa Branca. A guerra em estúdio: um cenário minuciosamente composto, trilha sonora, o tema do soldado refém/ herói que se resgata, a recorrência de sondagem da recepção pública mobilizada por comoções e campanhas e o viés das pesquisas e dos gráficos em que a campanha de reeleição indica uma linha ascendente. Numa expressão: mais do que a prevalência do virtual sobre o dado histórico; a pura virtualidade debruçando-se na criação dos efeitos de real.

\section{Palavras-chave}

1. Filosofia política

2. Imagem e discurso

3. Sociedade comunicacional

4. Política de dissuasão

5. Virtualização do real 